\title{
Correlation between bullying and clinical depression in adolescent patients
}

This article was published in the following Dove Press journal:

Adolescent Health, Medicine and Therapeutics

24 March 20II

Number of times this article has been viewed

\author{
Riittakerttu Kaltiala-Heino' \\ Sari Fröjd ${ }^{2}$ \\ 'University of Tampere Medical \\ School, Tampere, Finland; ${ }^{2}$ Tampere \\ School of Public Health, University \\ of Tampere, Finland
}

\begin{abstract}
A literature review of the associations between involvement in bullying and depression is presented. Many studies have demonstrated a concurrent association between involvement in bullying and depression in adolescent population samples. Not only victims but also bullies display increased risk of depression, although not all studies have confirmed this for the bullies. Retrospective studies among adults support the notion that victimization is followed by depression. Prospective follow-up studies have suggested both that victimization from bullying may be a risk factor for depression and that depression may predispose adolescents to bullying. Research among clinically referred adolescents is scarce but suggests that correlations between victimization from bullying and depression are likely to be similar in clinical and population samples. Adolescents who bully present with elevated numbers of psychiatric symptoms and psychiatric and social welfare treatment contacts.
\end{abstract}

Keywords: depression, bullying, adolescence

\section{Introduction}

About 10\%-20\% of children and adolescents are regularly involved in school bullying as either victims, bullies, or both. Boys are involved more often than girls, and a greater proportion of children than of adolescents report victimization from bullying. ${ }^{1-4}$ A growing body of research highlights the range of adverse consequences affecting individuals involved in bullying. Adolescents involved in bullying are at a significant risk of experiencing psychiatric symptoms, alcohol and drug abuse, and suicidal ideation or acts. ${ }^{1-4}$ The consequences of bullying may extend well into adulthood. Depression is one of the most prevalent mental health problems of adolescence. This paper reviews the literature on the correlation between depression and school bullying and attempts to evaluate whether there is evidence for causal relationships between the phenomena.

\section{Bullying}

Bullying is a subcategory of aggressive behavior. Aggressive behavior can be categorized according to its nature into overt/direct aggression (physical and verbal) and relational/indirect aggression (hostile manipulation of relationships by spreading ill-natured rumors, for example); and according to the motivation, into reactive (angry response to provocation or threat) and proactive (unprovoked, used for instrumental gain or dominance over others) aggression. ${ }^{5}$ Both proactive and reactive aggression may be associated with bullying, and both types of aggression may be used by the same perpetrator. ${ }^{6-8}$
Correspondence: Riittakerttu Kaltiala-Heino

Tampere University Hospital Pitkäniemi, 33380 Pitkäniemi, Finland

Tel +35833 I l63773

Email merihe@uta.fi 
There are several definitions of bullying in the literature. All of them share some features: bullying is considered intentional, repetitive, negative behavior that can manifest in many ways. A core element is also that bullying involves a power imbalance between the victim and the perpetrator. The literature identifies physical, verbal, and relational bullying. A novel phenomenon is bullying by electronic means, called cyberbullying. ${ }^{9,10}$ Verbal bullying is more common than physical bullying among adolescents of both sexes. ${ }^{11,12}$ Salmivalli et al have emphasized that bullying can be seen as a group phenomenon based on social relations and roles in the group. The phenomenon does not concern only the victim and the bully: the other pupils present may either support the perpetrator by their behavior, try to defend the victim, or withdraw. ${ }^{13}$

\section{Depression}

In literature, "depression" is used to refer to depressive affect; to depressive symptoms measured by symptom scales or self-reported depression; and to depressive disorders that fulfill the criteria in diagnostic classifications. In adolescence, mood changes are common. ${ }^{14}$ A depressive affect as a normative reaction to losses and failures can often be relieved by focusing on other aspects of life, and does not include impaired functioning. Self-reported depression measured by depression rating scales ranges from mild to severe. Moderate to severe self-reported depression in adolescence is likely to be fairly persistent and coincide well with clinically diagnosable depressive disorders. ${ }^{14,15}$ It may also be noted that adolescents remaining below the diagnostic criteria of a depressive disorder, yet displaying symptoms and impairment, may be chronically and clinically as impaired as those meeting full diagnostic criteria. ${ }^{16}$

The clinical diagnosis of a depressive disorder requires that the criteria for the disorder listed in diagnostic classifications (International Classification of Diseases by the World Health Organization (WHO) and Diagnostic and Statistical Manual of Mental Disorders by the American Psychiatric Association) are persistently met over a given period of time. Diagnostic interviews such as the Kiddie-Schedule for Affective Disorders and Schizophrenia (K-SADS) ${ }^{17}$ can be used to diagnose depressive disorders among clinically referred patients and in population studies. "Clinical depression" can be used to refer to conditions detected with structured diagnostic interviews, but also to depressive conditions that warrant referral to treatment. Rigorously diagnosed adolescents with depressive disorders in population and in clinical settings have been shown to be fairly similar. ${ }^{14}$

\section{Measuring bullying}

Being a complex phenomenon, bullying is not easy to measure. The most common way of measuring bullying behaviors is asking about personal experiences of it in surveys or interviews. The problem is that adolescents and researchers may not address the same phenomenon. To enhance mutual agreement between researchers and survey subjects on what bullying is, a description of the phenomenon measured may be included in the questionnaire. A good example of a scale with a description is The Revised Olweus Bullying/Victim Questionnaire, which is a measure with good psychometric properties. ${ }^{18}$ The widely used bullying questions recommended by WHO also include a description of what constitutes bullying, to be given before the respondent is asked to indicate how often $\mathrm{s} /$ he has been the victim of bullying or has bullied others during a defined time period. ${ }^{19}$ Victimization from bullying may also be studied by listing different aggressive behaviors (including calling names, spreading rumors, hitting, kicking, and excluding) and asking respondents to indicate which of them they have experienced and how often. Including a description of bullying in interviews or surveys decreases the reporting of victimization and increases the reporting of bullying. ${ }^{20}$

Another method to assess bullying behaviors is to use informants other than the child him/herself. Peer, parent and teacher nomination have been used to assess involvement in bullying, but individual incidents may be interpreted differently by observers and participants. Remarks intended as playful teasing may be interpreted as bullying, for example. It has been suggested that the level of agreement between informants on the occurrence of bullying and victimization is low. ${ }^{21}$ However, when using peer nomination, data on bullying is based on scores from multiple informants, which may increase reliability. Data from multiple informants is often aggregated when measuring bullying. This may be used to make the measurement more reliable. However, self-report and peer nomination may assess different attributes. ${ }^{22}$ Despite the methodological concerns, it is important also to study self-perceived bullying. The perception of being a victim of bullying may affect mood, even if the perception is false.

\section{Why could being a victim associate with depression?}

Public debate frequently associates victimization from bullying with depressive affect and disorders, assuming a causal relationship between being bullied and becoming depressed. The onset and recurrence of depressive disorders 
may be moderated or mediated by losses, abuse and ongoing conflicts or frustrations, ${ }^{23}$ and traumatic events, such as victimization to violence, predispose children and adolescents to depression. ${ }^{24}$ Victimization from bullying is likely to represent abuse, conflict and frustration. Particularly during adolescent development, when peer relationships are of utmost importance, ${ }^{25}$ traumatic events related to peer relationships, such as being bullied, could cause trauma severe enough to lead to depression. Increased emotional dysregulation and lowered self-esteem, following victimization from bullying, may act as mediators between being bullied and psychiatric symptoms such as depression. ${ }^{26,27}$ This may indicate that previous mental disorders mediate the association between depression and victimization. On the other hand, it is also possible that depression results in a distortion of the processing of social information: a depressive adolescent with negative self-perception may expect that others will behave in a rejective or hostile way and perceive this in social interactions that are meant by others to be neutral or even positive. ${ }^{28,29}$ Finally, it is also possible that the development of social skills and the ability to defend oneself are impaired among depressed adolescents, who therefore become easy targets for bullies. Depression in adolescence is known to impair social skills. ${ }^{14}$ The victims of bullying have been characterized as submissive and showing signs of helplessness, being less popular among peers, and displaying lowered self-esteem, ${ }^{27,30,31}$ all characteristics that may predispose them to victimization, but that are also possible antecedents of depression.

\section{Why could being a bully associate with depression?}

Bullies have been found to be characterized by externalizing behaviors or antisocial tendencies, such as overt aggressiveness, a tendency to manipulate, lack of empathy, and positive attitudes towards violence. ${ }^{32,33}$ The peer group has a significant association with aggressive behavior. Physical aggression may be normative in deviant peer groups, while adolescents higher in peer-perceived popularity may become more relationally aggressive over time. Aggressive behavior functions to gain or maintain social status in the selected peer group. ${ }^{3}$ The hypothesis that low self-esteem is associated with bullying others has recently been compromised by studies showing no association between bullying and self-esteem, or relatively high self-esteem in bullies. ${ }^{13,35,36}$ Being a bully has even been suggested to increase self-esteem in girls. ${ }^{37}$ It has been suggested that the aspect of control explains different types of bullying. Proactive aggression is especially associated with the need to control others, whereas reactive aggression is linked to deficits in self-control capability. ${ }^{8}$

Biased interpretations of social situations may be associated with reactive aggression in children or adolescents. ${ }^{5}$ However, deficits in processing social information among aggressive children may not explain all bullying behaviors. ${ }^{7}$ Some studies suggest that the perpetrators of relational aggression have higher levels of social intelligence than their peers. ${ }^{38}$

\section{Correlation between victimization from bullying and depression}

Many cross-sectional surveys in adolescent populations from different countries and in different phases of adolescent development have demonstrated an association between victimization from bullying and self-reported depression, ${ }^{2,4,39-46}$ and between being bullied and suicidality. ${ }^{2,39,43} \mathrm{~A}$ variety of depression scales and different self-report questionnaires, as well as the peer nomination method, have been used in these studies, but independently of methods, a correlation between victimization from bullying and depression has emerged in cross-sectional studies.

Cuevas et $\mathrm{al}^{47}$ studied psychiatric diagnosis as a risk factor for different kinds of victimization among children and adolescents. Depression was not addressed separately. Information was collected, using a structured questionnaire, from parents who reported treatment contacts due to nine different psychiatric diagnoses and victimization from various incidents. It was found that children and adolescents with a psychiatric diagnosis were more likely than those without a diagnosis to be victimized by a variety of assaults, including bullying.

Luukkonen et $\mathrm{al}^{48}$ studied the association between psychiatric diagnoses and involvement in bullying among adolescent psychiatric inpatients. The diagnoses were elicited in structured psychiatric assessments, and involvement in bullying was recorded as self-reported at the time of the psychiatric assessment. Among boys, victimization from bullying was associated with internalizing disorders, but among girls, no such association was found. Unfortunately, different diagnoses within the internalizing disorders were not studied separately. In another analysis, Luukkonen et $\mathrm{al}^{49}$ demonstrated that victimization from bullying was associated with suicidal behavior among female, but not among male, adolescent psychiatric inpatients.

Among adult patients presenting to an outpatient depression clinic, a history of victimization from bullying in childhood and adolescence was common, and it was 
associated with comorbid anxiety disorders among adults with clinical depression. ${ }^{50}$ Lund et $\mathrm{al}^{51}$ and Jordanova et $\mathrm{al}^{52}$ also reported that having been bullied at school was associated with an increased risk of clinical depression in adulthood. Longer and more intensive bullying posed a higher risk for depression. Among adult patients with anxiety disorders, having been bullied at school correlated with depression as well as with social anxiety and functional impairment. ${ }^{53}$ In these studies, however, experience of bullying was elicited retrospectively when the subjects presented with clinical disorders, and thus memory bias may influence the results. A further retrospective study among adult populations suggested that a history of bullying at school is associated with suicidal ideation well after completing school. ${ }^{54}$

Follow-up studies have suggested that victimization from bullying is an antecedent of emotional, behavioral, and psychosocial problems in both the short ${ }^{55,56}$ and the long run. ${ }^{57,58}$ On the other hand, internalizing and externalizing problems have been shown as antecedents of becoming victims of bullying. ${ }^{59-61}$ In a preadolescent sample, Fekkes et $\mathrm{al}^{62}$ showed that victimization was followed by psychosomatic, depressive and anxiety symptoms. In a population study among 10-17-year-old adolescents, victimization from bullying increased the risk of depression both with direct impact and through lowered self-esteem. ${ }^{27}$ The severity of bullying has been shown to predict persistence of depression among adolescent girls. ${ }^{63}$ Sourander et $\mathrm{al}^{64}$ found that among females (but not among males), victimization from bullying in childhood was predictive of psychiatric hospitalization and use of antidepressants, anxiolytics and antipsychotics by the age of 25 years, when childhood psychopathology was controlled for. Brunstein Klomek et al ${ }^{65}$ similarly reported that childhood victimization predicted suicide attempts and completed suicide by young adulthood only among girls, when controlled for childhood psychopathology. Due et $\mathrm{al}^{66}$ reported that victimization from bullying in adolescence predicted depression in young adulthood, and more clearly among socioeconomically-deprived adolescents than among those with affluent backgrounds.

However, there is also evidence that prior depression may predict subsequent victimization from bullying, or that the association between victimization and depression may be reciprocal. In a study by Fekkes et al, ${ }^{62}$ victimization emerged as an antecedent of depression, but depression and anxiety also predicted subsequent victimization from bullying. Sweeting et $\mathrm{al}^{30}$ found that victimization was associated with both past, concurrent, and future depression from ages 11 to 13 years and 13 to 15 years. Support was given both to the hypothesis that victimization causes depression and vice versa, but particularly to a bidirectional model. Among 15-year-old boys, however, only the pathway from prior depression to later victimization from bullying was confirmed. A reciprocal relationship between victimization and internalizing symptoms was also found in the study by McLaughlin et al. ${ }^{26}$ Bond et al, ${ }^{67}$ however, noted that victimization was predictive of depression and anxiety in girls, but that prior mental health problems were not predictive of victimization. Kaltiala-Heino et $\mathrm{al}^{68}$ found that when baseline depression was controlled, victimization from bullying emerged as an independent risk factor for later depression among boys, but not among girls. Among girls, depression predicted later experience of victimization.

Some longitudinal studies have, however, found no associations between victimization from bullying and depression. Brunstein Klomek et $\mathrm{al}^{69}$ reported that among boys, victimization from bullying at 8 years old did not predict depression or suicidality at 18 years old, and Kim et all ${ }^{70}$ found no association between involvement in bullying and depression (or anxiety) in any direction.

Follow-up studies on the association between victimization from bullying and depression have used different methods for assessing victimization and depression, but the findings are fairly similar irrespective of measures. Both short-term (within adolescence) and long-term (from childhood to adolescence or from childhood/adolescence until early adulthood) follow-up studies have mainly suggested that victimization from bullying increases the risk of depression later. If the pathway from prior depression to victimization later has been observed, it has also been confirmed in most studies.

\section{Depression in relation to being a bully}

Most studies on the association of bullying and depression focus on the depressive symptoms of the victims. An increasing concern is the mental health problems of the bullies. Several cross-sectional surveys have found elevated levels of depressive symptoms among school-aged youth

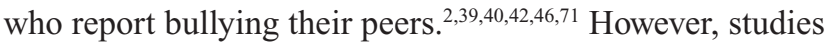
utilizing peer nomination to identify bullies have found no association between depressive symptoms and bullying. ${ }^{72,73}$ A study by Wienke Totura and colleagues ${ }^{21}$ examined differences among pupils identifying themselves as bullies and those identified by teachers as bullies. Self-reported bullying was associated with elevated levels of depressive symptoms, whereas teacher-reported bullying was not. 
Girls who report bullying others frequently may be at a significantly higher risk for depression and suicide attempts than comparable boys. ${ }^{2,42}$ Follow-up studies have suggested that reporting frequent bullying predicts subsequent depressive symptoms among males. ${ }^{58,68,69}$ In a nationally representative sample of US adults, the prevalence of major depression was found to be significantly higher among adults with a history of bullying compared to those who had not bullied others ( $31 \%$ versus $16 \%$ ), but the association became non-significant when sociodemographic background and history of psychiatric disorders were controlled for. However, the association between a history of bullying and subsequent bipolar disorder was sustained. ${ }^{74}$

The few studies conducted on clinical samples are mainly based on small numbers of patients; and bullies in particular are rare in these samples. Children bullying others have a fivefold risk of being in contact with mental health services compared to children with no involvement in bullying. ${ }^{75}$ Compared with psychiatric controls, bullies have been suggested to have a lower functional capacity. Patients recognized as bullies are more likely to present with externalizing than internalizing disorders, but major depression and depressive conduct disorder have been reported in association with bullying behavior. ${ }^{48,76}$ Female inpatients with a history of bullying others may have more than a threefold risk of suicide attempts compared to adolescent inpatients with no involvement in bullying. ${ }^{49}$ However, the first study conducted with a clinical cohort found no association between depressive disorders and being a bully in adolescence..$^{48}$

All adolescents with behavioral problems may not be treated in mental health settings. Individuals with depressive symptoms comorbid with antisocial behavior may end up in the juvenile justice system or in the custody of social services, depending on the service system of the country in question. As an example, more than $20 \%$ of females in juvenile detention met the criteria for a major depressive episode. ${ }^{77}$ Severe depressive symptoms and suicide attempts were highly prevalent among incarcerated juvenile offenders who were victimized and also bullied others. ${ }^{78,79}$

In addition to pure bullies and pure victims, bully victims or aggressive victims can be identified. In comparison to pure bullies, aggressive victims may be more prone to physically and less prone to verbally bully others, and may be more likely to be physically victimized than pure victims. Aggressive victims may have the inaccurate perception that peers intend to harm and therefore respond with physical aggression. Peers often dislike these aggressive victims. ${ }^{80}$
It has been found that adolescents who concurrently bully others and are victimized are at a higher risk of depression compared with pure bullies and pure victims. ${ }^{2,39}$

\section{Discussion}

So far, the literature is unable to inform us clearly about the association between victimization from bullying and clinical depression among adolescent psychiatric patients. Given that depressive disorders in the population bear a resemblance to those in clinical samples, and that self-reported depression in adolescence, when severe or even moderate, corresponds well with clinically diagnosable depression, ${ }^{14,15}$ there is reason to assume that, to some extent, victimization from bullying may predispose adolescents to depressive disorders. However, the association may also be vice versa: depression may predispose adolescents to victimization from bullying, or adolescents with depression may interpret nonhostile interactions as bullying. Prospective population studies with a structured diagnosis of depression, or reliable information about psychiatric treatment contact due to depression, could shed light on the issue.

Findings on gender differences in the association between victimization from bullying and depression have been contradictory. Our own research suggested that victimization increases the risk of depression among boys and depression is a risk factor for later victimization among girls, ${ }^{68}$ but others have suggested that an association between victimization and subsequent depression or self-harm is only or more strongly present among girls, ${ }^{65-67}$ or that depression may be an antecedent of later victimization, particularly among boys. ${ }^{30} \mathrm{It}$ has been suggested that victimization is more likely to result in low self-esteem in girls rather than boys, perhaps because adolescent girls may base their self-esteem more on social relationships than boys do, as boys focus on instrumental goals such as athletics and other achievements. ${ }^{27}$ However, as findings contradict, several pathways are likely to exist.

Whatever the direction of causality, the association between being bullied and depression may offer opportunities for prevention. If victimization from bullying predisposes adolescents to depression, reducing or preventing bullying might have an impact on adolescent depression. On the other hand, if the association is vice versa, victimization from bullying may nevertheless be a marker that helps identifying depressed adolescents or those at risk for depression.

Literature on the effect of bullying others on subsequent depression, or vice versa, is scarce and controversial. In particular, literature on actual depressive disorders in relation to being a bully is insufficient for making 
conclusions. Adolescents identifying themselves as bullies seem to be at risk for depressive symptoms, while bullies identified by others are not. This may indicate that identifying oneself as a perpetrator leads to feelings of shame and guilt and therefore to depression. Feelings of self-blame may also be symptoms of depression and lead to identifying oneself as a bully. Further studies are needed to confirm these differences, however. There may also be important differences between the sexes as regards the motivation and nature of aggressive behavior; and these may affect the association between depression and bullying others.

Psychiatric characteristics associated with bullying in youth may persist into adulthood. ${ }^{58,74}$ Bullying may place the perpetrator at risk for peer rejection, which, in turn, may increase depressive symptoms. Thus, interventions helping a depressed adolescent to stop bullying others may help in the healing process. In addition, the prevention of bullying behavior may reduce the incidence of depression. It is important to differentiate between two types of bullies: those who may have low self-esteem and deficient social skills and therefore use overt aggression; and those with relatively high self-esteem and a high status in the peer group, who use relational aggression to seek rewards at the expense of their victims. The interventions to stop bullying may not be the same for these groups. On the other hand, the same individuals may resort to both types of behavior. When treating adolescents in mental health settings, asking about bullying may be a good way of addressing aggressive feelings related to clinical depression.

If bullying others and depression are related because of psychiatric comorbidity, such as in cases of comorbid depression and conduct disorder, both disorders should be directly addressed in treatment. ${ }^{81}$

\section{Disclosure}

The authors report no conflicts of interest in this work.

\section{References}

1. Liang H, Flisher AJ, Lombard CJ. Bullying, violence and risk behavior in South African school students. Child Abuse Negl. 2007;31:161-171.

2. Brunstein Klomek A, Marrocco F, Kleinman M, Schonfeld I, Gould M. Bullying, depression and suicidality in adolescents. $J$ Am Acad Child Adolesc Psychiatry. 2007;46:40-49.

3. Nansel T, Overpeck M, Pilla R, Ruan W, Simons-Mortin B, Scheidt P. Bullying behaviors among US youth: prevalence and association with psychosocial adjustment. JAMA. 2001;285:2094-2100.

4. Carlyle K, Steinman K. Demographic differences in the prevalence, cooccurrence and correlates of adolescent bullying at school. $J$ Sch Health. 2007;77:623-629.

5. Marsee M, Weems C, Taylor L. Exploring the association between aggression and anxiety in youth: a look at aggressive subtypes, gender, and social cognition. J Child Fam Stud. 2008;17:154-168.
6. Miller J, Lynam D. Reactive and proactive aggression: similarities and differences. Pers Indiv Diff. 2006;41:1469-1480.

7. Wei H, Williams J. Instrumental or emotional aggression: testing models of bullying, victimization, and psychological maladjustment among Taiwanese seventh-graders. Soc Work Res. 2009;33:231-242.

8. Winstok Z. From self-control capabilities and the need to control others to proactive and reactive aggression among adolescents. $J$ Adolesc. 2009;32:455-466.

9. Stassen Berger K. Update on bullying at school: science forgotten? Dev Rev. 2007;27:90-126.

10. Elinoff MJ, Chafouleas SM, Sassu KA. Bullying: considerations for defining and intervening in school settings. Psychol Sch. 2004; 41:887-897.

11. Scheithauer H, Hayer T, Petermann F, Jugert G. Physical, verbal, and relational forms of bullying among German students: age trends, gender differences, and correlates. Aggress Behav. 2009;32:261-275.

12. Delfabbro P, Winefield T, Trainor S, et al. Peer and teacher bullying/ victimization of South Australian secondary school students: prevalence and psychosocial profiles. Br J Educ Psychol. 2006;76:71-90.

13. Salmivalli C, Kaukiainen A, Kaistaniemi L, Lagerspetz K. Selfevaluated self-esteem, peer-evaluated self-esteem, and defensive egotism as predictors of adolescents' participation in bullying situations. Pers Soc Psychol Bull. 1999;25:1268-1278.

14. Lewinsohn P, Rohde P, Seeley J. Major depressive disorder in older adolescents: prevalence, risk factors, and clinical implications. Clin Psychol Rev. 1998;18:765-794.

15. Charman T. The stability of depressed mood in young adolescents: a school-based survey. J Affect Disord. 1994;30:109-116.

16. Angold A, Costello J, Farmer E, Burns B, Erkanli A. Impaired but undiagnosed. J Am Acad Child Adolesc Psychiatry. 1999;38:129-137.

17. Kaufman J, Birmaher B, Brent D, et al. Schedule for affective disorders and schizophrenia for school aged children - present and life-time version (K-SADS-PL): initial reliability and validity data. J Am Acad Child Adolesc Psychiatry. 1997;36:980-988.

18. Kyriakides L, Kaloyirou C, Lindsay G. An analysis of the Revised Olweus Bully/Victim Questionnaire using the Rasch measurement model. Br J Educ Psychol. 2006;76:781-801.

19. King A, Wold B, Tudor-Smith C, Yossi H. The Health of Youth. A cross national survey. WHO regional publications, European series No 69, Canada, 1996.

20. Vaillancourt T, McDougall P, Hymel S, et al. Bullying: are researchers and children/youth talking about the same thing? Int J Behav Dev. 2008;32:486-495.

21. Wienke Totura C, Green A, Karver M, Gesten E. Multiple informants in the assessment of psychological, behavioral, and academic correlates of bullying and victimization in middle school. $J$ Adolesc. 2009;32: 193-211.

22. Cornell D, Sheras P, Cole J. Assessment of bullying. In: Jimerson S, Furlong M, Nickerson A, Mayer M, editors. Handbook of School Violence and School Safety: From Research to Practice. Princeton, NJ: Routledge; 2006.

23. Birmaher B, Brent D, AACAP Work Group on Quality Issues. Practice parameter for the assessment and treatment of children and adolescents with depressive disorders. J Am Acad Child Adolesc Psychiatry. 2007; 46:1503-1526.

24. Laugharne J, Lillee A, Janca A. Role of psychological trauma in the cause and treatment of anxiety and depressive disorders. Curr Opin Psychiatry. 2010;23:25-29.

25. Larson R, Richards MH. Daily companionship in late childhood and early adolescence: changing developmental contexts. Child Dev. 1991; 62:284-300.

26. McLaughlin K, Hatzenbuechler M, Hilt L. Emotion dysregulation as a mechanism linking peer victimization to internalizing symptoms in adolescents. J Consult Clin Psychol. 2009;77:894-904.

27. Turner H, Finkelhor D, Ormrod R. The effects of adolescent victimization on self-concept and depressive symptoms. Child Maltreat. 2010;15:76-90. 
28. Crick NK, Dodge KA. A review and reformulation of social information processing mechanisms in children's social adjustment. Psychol Bull. 1994;115:74-101.

29. Prinstein M, Cheah C, Guyer A. Peer victimization, cue interpretation, and internalizing symptoms: preliminary concurrent and longitudinal findings for children and adolescents. J Clin Child Adolesc Psychology. 2005;34:11-24.

30. Sweeting H, Young R, West P, Der G. Peer victimization and depression in early-mid adolescence: a longitudinal study. Br J Educ Psychol. 2006;7:577-594.

31. Scholte R, Engels R, Overbeek G, de Kemp R, Haselager G. Stability in bullying and victimization and its association. JAbnorm Child Psychol. 2007;35:217-228.

32. Carney A, Merrell K. Bullying in schools: perspectives on understanding and preventing an international problem. Sch Psychol Int. 2001;22: 364-382.

33. Sutton J, Keogh E. Social competition in school: relationships with bullying, Machiavellism and personality. Br J Educ Psychol. 2000;70: 443-446.

34. Pokhrel P, Sussman S, Black D, Sun P. Peer group self-identification as a predictor of relational and physical aggression among high school students. J Sch Health. 2010;80:249-258.

35. Seals D, Young J. Bullying and victimization: prevalence and relationship to gender, grade level, ethnicity, self-esteem, and depression. Adolescence. 2003;38:735-747.

36. Kaukiainen A, Salmivalli C, Lagerspetz K, et al. Learning difficulties, social intelligence and self-concept: connections to bully-victim problems. Scand J Psychol. 2002;43:269-278.

37. Pollastri AR, Cardemil EV, O'Donnell EH. Self-esteem in pure bullies and bully/victims: a longitudinal analysis. J Interpers Violence. 2010; 25:1489-1502.

38. Andreou E. Social preference, perceived popularity and social intelligence: relations to overt and relational aggression. Sch Psychol Int. 2006;27(3):339-351.

39. Kaltiala-Heino R, Rimpelä M, Marttunen M, Rimpelä A, Rantanen P. Bullying, depression, and suicidal ideation in Finnish adolescents: school survey. Br Med J. 1999;319:348-351.

40. Kaltiala-Heino R, Rimpelä M, Rantanen P, Rimpelä A. Bullying at school - an indicator of adolescents at risk for mental disorders J Adolesc. 2000;23:661-674.

41. Fekkes M, Pijpers FI, Verloova-Vanhorick SP. Bullying behavior and associations with psychosomatic complaints and depression in victims. J Pediatr. 2004;144:17-22.

42. Saluja G, Iachan R, Scheidt P, Overpeck M, Sun W, Giedd J. Prevalence of and risk factors for depressive symptoms among young adolescents. Arch Pediatr Adolesc Med. 2004;158:760-765.

43. Kim YS, Koh YJ, Leventhal B. School bullying and suicidal risk in Korean middle school students. Pediatrics. 2005;115:357-363.

44. Pittet I, Berchtold A, Akré C. Are adolescents with chronic conditions particularly at risk for bullying? Arch Dis Child. 2010;95: 711-716

45. Fleming L, Jacobsen K. Bullying and symptoms of depression in Chilean middle school students. J Sch Health. 2009;79:130-137.

46. Fitzpatrick K, Dulin A, Piko. Bullying and depressive symptomatology among low-income, African-American youth. J Youth Adolesc. 2010; 39:634-645.

47. Cuevas C, Finkelhor D, Turner H. Psychiatric diagnosis as a risk marker for victimization in a national sample of children. J Interpers Violence. 2009;24:636-652.

48. Luukkonen A-H, Räsänen P, Hakko H, Riala K. Bullying behavior in relation to psychiatric disorders and physical health among adolescents: a clinical cohort of 508 underage adolescents in Northern Finland. Psychiatry Res. 2010;178:166-170 (a).

49. Luukkonen A-H, Räsänen P, Hakko H, Riala K. Bullying behavior is related to suicide attempts but not to self-mutilation among psychiatric inpatient adolescents. Psychopathology. 2009;42: 131-138.
50. Gladstone G, Parker G, Malhi G. Do bullied children become depressive and anxious adults? A cross-sectional investigation of the correlates of bullying and anxious depression. J Nerv Ment Dis. 2006; 194:201-208.

51. Lund R, Kragelund Nielsen K, Hjorth Hansen D, et al. Exposure to bullying at school and depression in adulthood: a study of Danish men born in 1953. Eur J Public Health. 2008;19:111-116.

52. Jordanova V, Stewart R, Goldberg D, et al. Age variation in life events and their relationship with common mental disorders in a national survey population. Soc Psychiatry Psychiatr Epidemiol. 2007;42: 611-616.

53. McCabe R, Miller J, Laugesen N, Anthony M, Young L. The relationship between anxiety disorder in adults and recalled childhood teasing. J Anxiety Disord. 2010;24:238-243

54. Roeger L, Allison S, Korossy-Horwood R, Eckert K, Goldney R. Is a history of school bullying victimization associated with adult suicidal ideation? J Nerv Ment Dis. 2010;198:728-733.

55. Hanish LD. Guerra NG. A longitudinal analysis of patterns of adjustment following peer victimization. Dev Psychopathol. 2002;14:69-89.

56. Ladd GW, Troop-Gordon W. The role of chronic peer difficulties in the development of children's psychological adjustment problems. Child Dev. 2003;74:1344-1367.

57. Kumpulainen K, Räsänen E. Children involved in bullying at elementary school age: their psychiatric symptoms and deviance in adolescence. An epidemiological sample. Child Abuse Negl. 2000;24: 1567-1577.

58. Sourander A, Jenson P, Rönning JA, et al. What is the early adulthood outcome of boys who bully or are bullied in childhood? The Finnish "from a boy to a man" study. Pediatrics. 2007;120:397-404.

59. Boulton M, Smith PK. Bully/victim problems in middle school children: stability, self-perceived competence, peer perceptions and peer acceptance. Br J Dev Psychol. 1994;12:315-329.

60. Hodges E, Perry D. Personal and interpersonal antecedents and consequences of victimization by peers. J Pers Soc Psychol. 1999;76: 677-685.

61. Sourander A, Helstelä L, Helenius H, Piha J. Persistence of bullying from childhood to adolescence - a longitudinal 8-year follow up study. Child Abuse Negl. 2000;24:873-921.

62. Fekkes M, Pijpers F, Fredriks A, Vogels T, Verloove-Vanhorick S. Do bullied children get ill, or do ill children get bullied? A prospective cohort study on the relationship between bullying and health-related symptoms. Pediatrics. 2006;117:1568-1574.

63. Patton G, Olsson C, Bond L, et al. Predicting female depression across puberty: a two-nation longitudinal study. J Am Acad Child Adolesc Psychiatry. 2008;47:1424-1432.

64. Sourander A, Ronning J, Brunstein-Klomek A, et al. Childhood bullying behavior and later psychiatric hospital and psychopharmacologic treatment. Arch Gen Psychiatry. 2009;66:1005-1012.

65. Brunstein Klomek A, Sourander A, Niemelä S, et al. Childhood bullying behaviors as risk for suicide attempts and completed suicides: a population-based cohort study. J Am Acad Child Adolesc Psychiatry. 2009;48:254-261.

66. Due P, Damsgaard MT, Lund R, Hostein B. Is bullying equally harmful for rich and poor children? A study of bullying and depression from age 15 to 27. Eur J Public Health. 2009;19:464-469.

67. Bond L, Carlin J, Thomas L, Rubin K, Patton G. Does bullying cause emotional problems? A prospective study of young teenagers. Br Med J. 2001;323:480-484.

68. Kaltiala-Heino R, Fröjd S, Marttunen M. Involvement in bullying and depression in a 2-year follow-up in middle adolescence. Eur Child Adolesc Psychiatry. 2010;19:45-55.

69. Brunstein Klomek A, Sourander A, Kumpulainen K, et al. Childhood bullying as a risk factor for later depression and suicidal ideation among Finnish males. J Affect Disord. 2008;109:47-55.

70. Kim YS, Leventhal B, Koh Y-J, Hubbard A, Boyce T. School bullying and youth violence: causes or consequences of psychopathologic behavior? Arch Gen Psychiatry. 2006;63:1035-1041. 
71. van der Wal MF, Wit CA, Hirasing RA. Psychosocial health among young victims and offenders of direct and indirect bullying. Pediatrics. 2003;111:1312-1317.

72. Camodeca M, Goossens FA. Aggression, social cognitions, anger and sadness in bullies and victims. J Child Psychol Psychiatry. 2005;46: 186-197.

73. Juvonen J, Graham S, Schuster MA. Bullying among young adolescents: the strong, the weak, and the troubled. Pediatrics. 2003;112: 1231-1237.

74. Vaughn M, Fu Q, Bender K, et al. Psychiatric correlates of bullying in the United States: findings from a national sample. Psychiatr Q. 2010; 81:183-195.

75. Kumpulainen K, Räsänen E, Puura K. Psychiatric disorders and the use of mental health services among children involved in bullying. Aggress Behav. 2001;27:102-110.

76. Salmon G, James A, Cassidy EL, Auxiliadora Javaloyes M. Bullying a review: presentations to an adolescent psychiatric service and within a school for emotionally and behaviorally disturbed children. Clin Child Psychol Psychiatry. 2000;5:563-579.
77. Teplin L, Abram K, McClelland G, Dulcan M, Mericle A. Psychiatric disorders in youth in juvenile detention. Arch Gen Psychiatry. 2002;59: 1133-1143.

78. Ireland J. Psychological health and bullying behavior among adolescent prisoners: a study of young and juvenile offenders. J Adolesc Health. 2005;36:236-243.

79. Viljoen J, O’Neill M, Sidhu A. Bullying behaviors in female and male adolescent offenders: prevalence, types, and association with psychosocial adjustment. Aggress Behav. 2005;31:521-536.

80. Unnever J. Bullies, aggressive victims, and victims. Aggress Behav. 2005;31:153-171.

81. Rohde P, Clarke G, Mace D, Jorgensen J, Seeley J. An efficacy/ effectiveness study of cognitive-behavioral treatment for adolescents with comorbid major depression and conduct disorder. J Am Acad Child Adolesc Psychiatry. 2004;43:660-668.

\section{Publish your work in this journal}

Adolescent Health, Medicine and Therapeutics is an international, peer-reviewed, open access journal focusing on health, pathology, and treatment issues specific to the adolescent age group. All aspects of health maintenance, preventative measures and disease treatment interventions are addressed within the journal and practitioners from all disciplines are invited to submit their work as well as healthcare researchers and patient support groups.. The manuscript management system is completely online and includes a very quick and fair peerreview system. Visit http://www.dovepress.com/testimonials.php to read real quotes from published authors.

Submit your manuscript here: http://www.dovepress.com/adolescent-health-medicine-and-therapeutics-journal 